\title{
Some Nickel-Iron, and Nickel-Metal Hydride, Cell Cycling Results by
}

Brian J. Dougherty, Francis L. Tanzella, SRI International, 333 Ravenswood Ave. Menlo Park CA 94025 and

Robert D. Weaver, Weaver Consulting, 777 Wildwood Lane, Palo Alto, CA 94303

\begin{abstract}
Some cycling experiments were performed on two kinds of cells: Nickel-Iron and NickelMetal-Hydride. A nominal 200 Ampere-hour Nickel-Iron battery was obtained from EaglePicher, Inc. and its initial capacity was determined by cycling at the manufacturer's recommended regime. A single cell was removed from the battery and placed in a cell case designed to provide for quantitative assay of all gases evolved. After determining that no change in ampere-hour capacity of the cell had occurred as a result of the handling of the cell, the cell capacity was reduced to 15 ampere-hours in a negative-positive-negative configuration by removal of plates and by cutting the remaining plates to approximately one-half the original area. The resultant cell displayed the calculated capacity. At this time the charging regime was changed to include high rate DC, up to $6 C$, and various forms of non-DC charging, again at high rates. During these experiments, careful assay of the instantaneous quantities of hydrogen and oxygen were performed using gas chromatography. No significant effects of kinds of charging currents upon quantities of gases evolved were found. Very difficult-to-interpret results representing the quantity of gas evolved as a function of state of charge were observed. The well-known ruggedness of the Edison couple was observed during the study which subjected the cell to three year's worth of time and many non-standard and otherwise abusive charging conditions; the capacity of the cell did not change during all of this.
\end{abstract}

Some Nickel-Metal-Hydride cells were subjected to cycling experiments. The cells were of generic manufacture intended for use in lap-top computers; the capacity was at the 2 ampere-hour level. A pressure-measuring transducer was affixed to cells under study in such a way that the interior gaseous content of a cell was not allowed to escape, and the void volume of the cell system was not increased by more than about $0.5 \mathrm{ml}$. Pressure versus state-of-charge results at various temperatures are presented.

\section{Introduction}

Two battery systems of interest for use in electric vehicles were chosen for study of some of their characteristics. The Nickel-Iron battery is well known for its ruggedness and energy content relative to the Lead-Acid battery. The NickelIron battery is also known for its high rate of water consumption; the gassing rate, especially during charging, is the highest among the commercial aqueous battery systems. Various benefits have been claimed for Non-DC charging, including exceptionally high rate charging (Ref. 1.). Accordingly, a study of the charging of a representative Nickel-Iron battery was made. A commercial 6-volt, 200 ampere-hour, module was used as the test bed for the experiments.

The second battery system chosen was the Nickel-Metal-Hydride battery. This battery is related to the Nickel-Hydrogen battery of space use whose long life is well documented; the hydrogen is stored at high pressure in that battery and the battery displays a relatively high self-discharge. rate The Nickel-Metal-Hydride battery is being manufactured in large quantities at this time for use in portable computers. It was of interest, therefore, to investigate the pressure and self discharge characteristics of some Nickel-MetalHydride cells that were then available.

The information contained in this paper is a condensation of a much more detailed account of the work performed under the EPRI-sponsored project (Ref. 2.). The final report will be available in early 1995 from EPRI.

\section{Equipment and Procedures}

The Nickel-Iron module. A prismatic, five-cell, 200-Ah, Ni-Fe Module (NIF-200-5) was obtained from Eagle-Picher under the auspices of EPRI which had had such modules constructed for use in electric vehicles. The specifications for the electrolyte and the details of construction were made available to SRI to facilitate the research and to assure proper treatment of the cells. At the time of delivery, the module had received 66 cycles at Eagle Picher. The sequence of tests applied was to cycle the module to confirm its survival of charged- 
stand and shipment stresses; the charged-stand time was several months. After confirmation cycling, a cell was removed from the module and placed in a case made of two-inch thick plates of polyethylene. The design was such as to ensure no-leak management of the gas streams involved in assay of evolved gases.

Cycling of the single 200-Ah cell was continued until quantitative gas composition and evolution rate data had been successfully obtained. At that time, the 21-plate cell, made of 11 negatives and 10 positives, was removed from the case and sufficient plates were removed, and remaining plates cut in area, so that the resulting plates, still attached to the original spider system, represented a cell that would display a calculated capacity of 14.5 Ah. The space within the cell case that was made available by this reduction in volume was filled with plates of polyethylene and the small-capacity cell was replaced in the polyethylene case. The reduced capacity of the small cell allowed high-rate charging, up to $6 \mathrm{C}$, to be performed.

The time span for this work was three years. The relationship between kind of test, cycle number, and time, is shown in Figure 1.

The Nickel-Metal-Hydride Cells. Tests of $\mathrm{Ni}-\mathrm{MH}$ cells were made using cells sold commercially for use in lap-top computers. The cylindrical cells were $2.2 \mathrm{Ah}$ in capacity and were 1.6 $\mathrm{cm}$ in diameter and $6.4 \mathrm{~cm}$ long. It was found, by disassembly, that the cells were of spirally wound construction. Studies of the cycling characteristics of the cells were made by constant-current cycling. The cycling was performed at various temperatures to obtain a relationship between temperature and self discharge rates. Measurements were made of the pressure changes associated with cycling.

Cycling Circuitry. The module or cells were cycled at constant current, both charge and discharge. The charge regime was terminated by a time limit, with a voltage limit $(1.5 \mathrm{~V}$ for $\mathrm{Ni}-\mathrm{MH}$ and $1.75 \mathrm{~V}$ for $\mathrm{Ni}-\mathrm{Fe}$ ) as a second end-of-charge limit. The discharge half cycle was terminated by a voltage limit of $1.0 \mathrm{~V}$ for both systems. The charging regime recommended by Eagle Picher was $54 \mathrm{~A}$ for 5 hours; this corresponds to a $35 \%$ overcharge at the $C /(3.7)$ rate. The circuitry used was of the type shown in Figure 2. The DC power supply (Sorensen DCS 8-125) was capable of supplying ripple-free direct current at 8 Volts and 125 Amperes.

Hydrogen-Oxygen Analyses. The gases evolved during charging $(\mathrm{Ni}-\mathrm{Fe}$ only) were quantitatively assayed using gas-phase chromatog- raphy. A six-foot, 1/8 inch diameter, stainless steel, molecular sieve column (Alltech 5605PC) was used for the separation of hydrogen, oxygen, and nitrogen. The temperature of the column was maintained at $40{ }^{\circ} \mathrm{C}$ and the detector was held at $100^{\circ} \mathrm{C}$. A stream splitter approach was necessary because of the high-rate of evolution of gases, especially near end of charge. (A fully-charged 5cell module undergoing a 54 A charging current will evolve over three liters of the $\mathrm{H}_{2}$ and $\mathrm{O}_{2}$ stoichiometric mixture each minute.) Gases were automatically sampled at three-minute intervals by use of a zero-dead-volume injection valve with a 1 $\mathrm{ml}$ sample loop.

Data Acquisition. Data were acquired with a Macintosh Plus computer using an IOTech, Inc. Mac488B Macintosh-to-IEEE-488 interface to a Keithley multimeter. The multimeter was model $199 / 1992$ with a 5-1/2 digit display and 8 channel scanning capacity.

Pressure Measurements. Pressure measurements of the $\mathrm{Ni}-\mathrm{MH}$ cells were made using an Omega Model PX 613 Pressure Transducer. The transducer output was fed to the Keithley Multimeter. The transducer was attached to $1 / 8$ th inch OD tubing in the manner shown in Figure 3. The 1/8th tubing was silver soldered into 1/2-inch diameter brass bodies as shown in the figure. One of the bodies was glued, using epoxy glue, to the end of the $\mathrm{Ni}-\mathrm{MH}$ cell. The brass body and the $1 / 8$ th inch tubing that were in line with the axis of rotation of the cell's body were terminated at the other end with a drill-rod fitting, which allowed a 1/16th inch drill rod to be centered down the tubing. The drill rod was terminated with number 40 twist drill. The fitting provided for an " $O$ " ring seal to the drill rod. The tubing shown that is perpendicular to the axis was attached to a gas manifold system that provided first for the evacuation of the transducer plumbing, then for back fill with hydrogen. At this point, the transducer system was filled with $\mathrm{H}_{2}$ gas at a pressure expected to exist within the cell. It was found that this system could withstand a pressure of 100 psig for 2 days with no measurable change in pressure. The transducer was then coupled to the interior of the cell by pressing on the drill rod until the twist drill touched the case of the cell, at which time the drill rod was rotated and the case of the cell breached by the drill. The rod was then extracted to a point that allowed the tubing to be bent, crimped, and sealed. The volume of the pressure transducer system was measured (by filling with 
water and weighing) as $0.5 \mathrm{ml}$. The void volume of cell was found to be $2 \mathrm{ml}$, so the addition of the added volume of the transducer had at most a $25 \%$ effect on internal pressure. In fact, if the cell were filled with $\mathrm{H}_{2}$ gas and if the guess made about internal pressure was correct when filling the transducer's manifold system, then no error in measurement of initial pressure would have been made, and only the capacity of the cell might have been altered.

Non-DC Charging. URAC One of the non-pure DC wave forms frequently encountered in charging batteries is the current resulting from the use of unfiltered, full-wave rectified, alternating current as the charging current. This is frequently encountered simply because it results from the use of a full-wave bridge circuit that has no filtering components such as choke coils or input capacitors, both of which are expensive. The output of such a circuit is that of a sine wave in which all negative-going pulses have been flipped to be positive; the output is unidirectional, that is, it is DC, but it is not steady-state DC. This URAC was provided for by winding a secondary coil about the core of a $1.5 \mathrm{~kW}$ autotransformer. The centertapped secondary was fed to two diodes of appropriate current capacity. The output of the system was variable from zero to 5 volts and could deliver up to 200 peak amperes.

Non-DC Charging. Pulsed-Discharge Charging. The charging of cells using a form of current containing sequential charge and discharge pulses was accomplished using the circuit of Figure 4. The Sorensen DC power supply described above was used for the charging current which was allowed to flow into the cell for a period of $990 \mathrm{~ms}$. The triggering circuit then activated the two parallel MOSFET transistors to the nonconducting state at which time the DC current was stopped. A rest period of $1 \mathrm{~ms}$ was allowed during which no current was allowed to flow into or out of the cell. Following this period, the triggering circuit then activated the four MOSFET transistors that were ganged in parallel across the cell's terminals. This then turned the transistors into the conducting mode and the cell's voltage was sufficient to allow currents as high as 70 amperes to flow. This was a discharge pulse and was allowed to flow for only $10 \mathrm{~ms}$. The pulse was then followed by another rest period of $1 \mathrm{~ms}$. Thus, this waveform had repetition rate of essentially $1 / \mathrm{sec}$. It will be recognized that the waveform chosen is but one of myriad possible choices, but it is believed that it is representative of many of the forms of pulsed charge/discharge waveforms now being investigated.

Electrometer Studies. A Keithley Model 610 Electrometer was used in an attempt to determine the presence of static charges on spray drops emerging from the cell. The electrometer was attached to a nickel screen placed in the cell's emergent gas stream.

Ring-Disk Cyclic Voltammetry. A pure iron disk was coupled to a platinum ring in a Pine Co. Ring-Disk stand. The dual potentiostat used was a Pine Model RDE3.

\section{$\mathrm{Ni}-\mathrm{Fe}$ Results}

Literature search. A search of the literature was made at the outset of the project. The object was to determine the extent of interest in various unconventional kinds and rates of charging of batteries. It was found that there was interest in highrate charging of batteries to times as short as 10 minutes. Also, various kinds of charging currents, other than pure DC, were being investigated for beneficial effects upon efficiency, charge acceptance, and parasitic losses. The results of the search are presented in the final report of this work, Reference 2.

$\mathrm{Ni}-\mathrm{Fe}$ Stability. The ruggedness of the Edison cell is well recognized. In the course of this study, the cell system underwent months of charged-stand, 250 charge-discharge cycles, all of which were to $100 \%$ depth of discharge, was subjected to extremes of rates of charge, was disassembled several times, and all the while the cell retained its normalized original capacity; the inherent superiority of the system in these areas has again been demonstrated. The flatness of the capacity with time-cycling curve of Figure 1 is remarkable. The lines, one above and the other below the bold line at 200 Ah represent the upper, $204 \mathrm{Ah}$, and the lower, $194 \mathrm{Ah}$, of the observed normalized capacities during the period of this research. The normalized capacity refers to multiplying the observed capacity of the nominal 14.5 Ah cell by the factor 200/14.5; results obtained under non-standard conditions were not included in this statement. Non-standard conditions include those following addition of water, equipment failure, long-stand capacity measurements, and the like.

Evolution of $\mathrm{H}_{2}$ and $\mathrm{O}_{2}$. The electrodes of the $\mathrm{Ni}-\mathrm{Fe}$ system are thermodynamically unstable with respect to the concentrated basic aqueous 
electrolyte employed. A study of the thermodynamic relationships (Ref. 2.) was made and no conditions that would lead to stability were found. Accordingly, it is certain that the $\mathrm{Ni}-\mathrm{Fe}$ cell will react with the water to release oxygen and hydrogen; the rates are in question.

The $\mathrm{Ni}-\mathrm{Fe}$ cell was found to release hydrogen at a relatively uniform, but low, rate while under charged-stand. The rate of oxygen release during the same time was considerably lower, and was below the detection limit of our instrumentation $(2 \mu \mathrm{l} / \mathrm{min})$. The actual rates of evolution depend upon whether the period in question is discharged- or charged-stand and on how recently the cell was taken off charge. All data for the $\mathrm{Ni}-\mathrm{Fe}$ system are at a nominal room temperature ranging between $20^{\circ}$ and $25^{\circ} \mathrm{C}$.

The rates of release of gases during charging were inconsistent with the belief, held at the start of this work, that the gas evolved, especially at end of charge, had to be a stoichiometric mixture of $\mathrm{H}_{2}$ and $\mathrm{O}_{2}$; after all, when the cell is fully charged, only the electrolysis of water can sustain the continued passage of current. Now, in fact, this was found to be the case, but only after an overcharge of some $50 \%$. A representative instantaneous ratio of $\mathrm{H}_{2}$ to $\mathrm{O}_{2}$ is shown in Figure 5.

The quantities of $\mathrm{H}_{2}$ and $\mathrm{O}_{2}$ evolved were calculated from the instantaneous chromatographic data and a running total was made for each run. Data representing a typical charge cycle are also presented in Figure 5.

Effect of URAC Charging. The unfiltered, rectified alternating current, current was set to have a time-average charging value equivalent to the use of direct current, and this was applied to the cell so that full charge would be accomplished in the same time span. The charging efficiency and capacity of the cell was found to be unaltered. Results for both are compared in Figure 6.

Static Charge on Entrained Droplets. The possibility that explosions of the evolved gases might be caused by discharge of static charges accumulated from drops of electrolyte entrained in the gas stream was checked by use of the electrometer and insulated screen placed in the gas stream. At no time was a build up of charge observed.

Rotating Ring-Disk Studies. The iron disk, operated anodically, formed iron oxides as indicated by its change in potential, but at no time was a ring current observed that was above the background.
Mucic Acid Additions. The addition of mucic acid to the plates of a $\mathrm{Ni}-\mathrm{Fe}$ cell during formation has been reported to reduce the gassing rate (Ref. 3.). Accordingly, a saturated solution made of mucic acid and the electrolyte was added to the cell. No change in gassing rate was observed.

\section{$\mathrm{Ni}-\mathrm{MH}$ Results}

Self-Discharge with Temperature. The cell was charged and the discharge capacity was measured after various times of charged stand. The capacity after one-half hour of charged stand was taken as the representative capacity for the temperature of the test. The results are presented below.

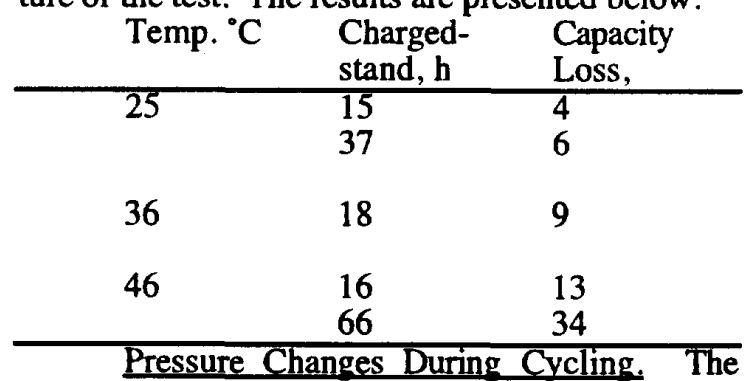
internal pressure of the cell was measured during cycling. The pressure was found to change with charging, but most change occurred in the last two hours of a seven-hour charge period. The pressure within the discharged cell was found to be very close to $0 \mathrm{psig}$, usually less than $5 \mathrm{psig}$, and the maximum pressure rise observed was 25 psig. The pressure tended to decrease immediately upon the cell's being placed on open circuit. Discharge was started one-half hour after end of charge and the pressure fell in a rather hyperbolic fashion back to the starting pressure by the end of the five-hour discharge.

Voltage During Cycling at Various Temperatures. The voltage of $\mathrm{Ni}-\mathrm{MH}$ cylindrical cells during cycling at various temperatures was measured. Typical results are presented in Figure 7.

Influence of Hydrogen Gas Inventory upon Capacity. To determine whether hydrogen in the gas phase would affect (increase) the discharge capacity of the $\mathrm{Ni}-\mathrm{MH}$ cylindrical cells, the pressure measuring manifold of Fig. 3 was attached to a reservoir of $\mathrm{H}_{2}$; the pressure and volume were such that the capacity of the cell could have been increased from 2.0 to $3.2 \mathrm{Ah}$ had the cell been negative limited. No increase in capacity was observed. 


\section{Discussion}

The measurement of kinds and rates of evolution of gases is of paramount importance to a study of this type. It is now clear that the use of two separate gas chromatograph columns, each fed by a simultaneously-activated automatic switch, would have simplified the interpretation of chromatographic results and would have increased the accuracy of those results. Nevertheless, the data obtained with the equipment employed certainly functioned well to define the trends of gassing.

The studies of URAC charging are of particular interest because this wave form is so frequently encountered in charging of batteries. No beneficial, or deleterious, effects upon gassing rates were found in this study. However it must be emphasized that the increases in temperature and losses of energy efficiency were not measured in this study. Note that the use of URAC-type currents must involve a $25 \%$ loss in energy efficiency (Ref. 3., Appendix)

The circuit used in the Pulsed-Discharge work takes advantage of the unique characteristics of the MOSFET transistors used; these devices allow a parallel arrangement of load elements for increases in current-handling ability while not requiring the use of series current-balancing resistors. Because of this, the solid-state devices could be used as high-current loads for the cell while using the voltage of the cell as the sufficient driving force.

Considering the abuse to which the plates were subjected- in one instance the plates received an extended overcharge due to equipment failure - the observed constancy of the normalized capacity is remarkable.

It is clear from the results obtained that all attempts to reduce the gassing rate, or to achieve high-rate charging at lessened voltages, were unsuccessful. The use of URAC, Reversed-Pulse charging, or addition of mucic acid did not decrease the gassing rate. It should be mentioned here that it was not possible to add mucic acid to the plates at the time of manufacture; addition via the electrolyte may not be the equivalent to the method described in the patent.

The changes in composition, of the electrolyte and within the electrode, that occur in the $\mathrm{Ni}-\mathrm{Fe}$ cell during a number of cycles are of interest. The non-stoichiometric evolution of $\mathrm{H}_{2}$ must mean that the positive electrode is undergoing oxidation to a product other than $\mathrm{O}_{2}$. This continues during charged- or discharged-stand because, although the rates are low, it is still $\mathrm{H}_{2}$ that dominates the composition of the evolved gas. The addition of water, usually required after five full cycles, affected the activity of water to such an extent that quite noticeable changes in composition of the gas were required to achieve balance so that the integrand of all gases evolved eventually represented a composition of two $\mathrm{H}_{2}$ to one $\mathrm{O}_{2}$.

Although some speculation exists that build up of static charge on entrained droplets in the spray emerging from a cell being charged might account for explosions, the simple apparatus used to detect such possible charges was unable to do so. More attention to experimental design, to assure true absence of leakage paths, would be required to either detect such charges or negate the hypothesis.

The interesting $\mathrm{Ni}-\mathrm{MH}$ system did not involve high internal pressures. Some negative pressures, -psig, were sometimes observed for a discharged cell. The highest internal pressure, observed at the end of charge, was usually less than 30 psig.

The self-discharge rates of the system suggest that elevated temperatures are to be avoided in use, and that reduction is self-discharge reactions would be beneficial.

One might assume that $\mathrm{H}_{2}$ in the gaseous phase would be electrochemically active at the surface of the negative electrode material. One might further assume that cost considerations would tend to favor balance between the capacity of the electrodes of the cell that would result in a negativelimited design. The failure to observe any increase in capacity in the cell upon the addition of a reserve supply of hydrogen remains unexplained.

\section{Acknowledgment}

The authors wish to express their gratitude to the Electric Power Research Institute for support of this research. Special thanks are also due Drs. S. Smedley and M. McKubre of SRI International and Dr. Fritz Kalhammer of EPRI for their many helpful suggestions.

\section{References}

1. Y. Podrazhansky and P. Popp, "Rapid Battery Charger, Discharger and Conditioner", US Patent $4,829,225,(1989)$

2. EPRI Report for Project RP 8002-25. To be published.

3. M. J. Mackenzie and A. J. Salkind, "Gas Depressor Additives for Iron Electrodes", US Patent 3,484,291, (1969) 


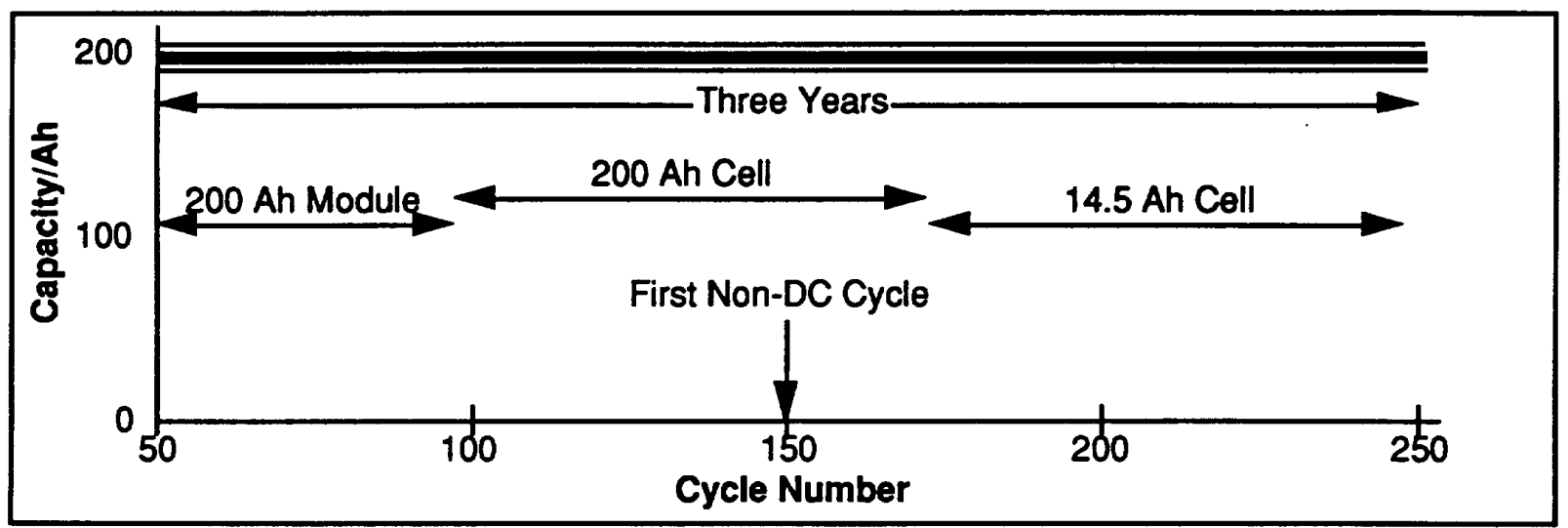

Figure 1. The relationship between kind of test, cycle number, time, and capacity.

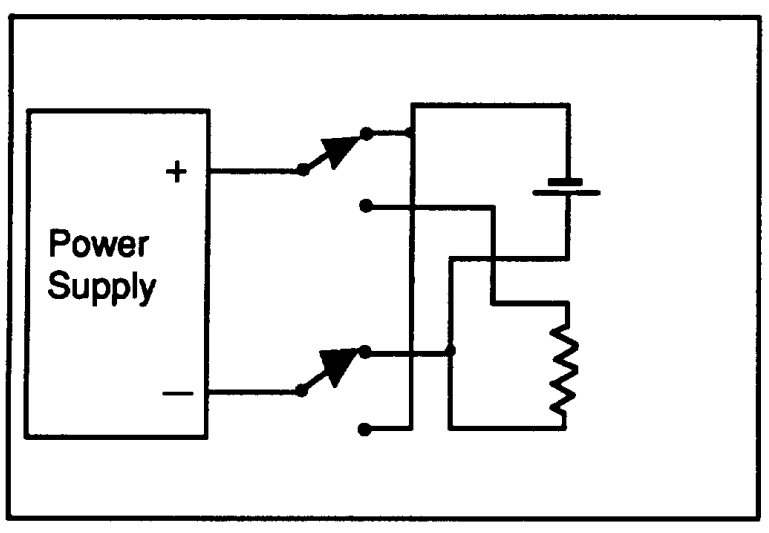

Figure 2. Generalized cycling circuit.

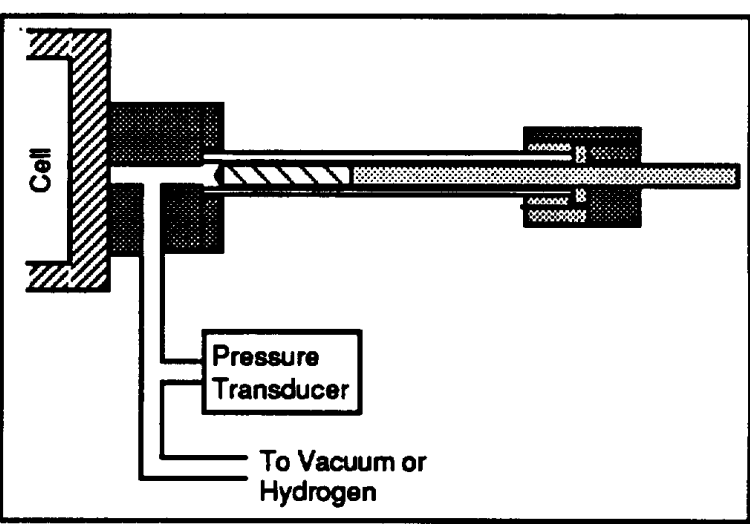

Figure 3. Pressure transducer assembly. 


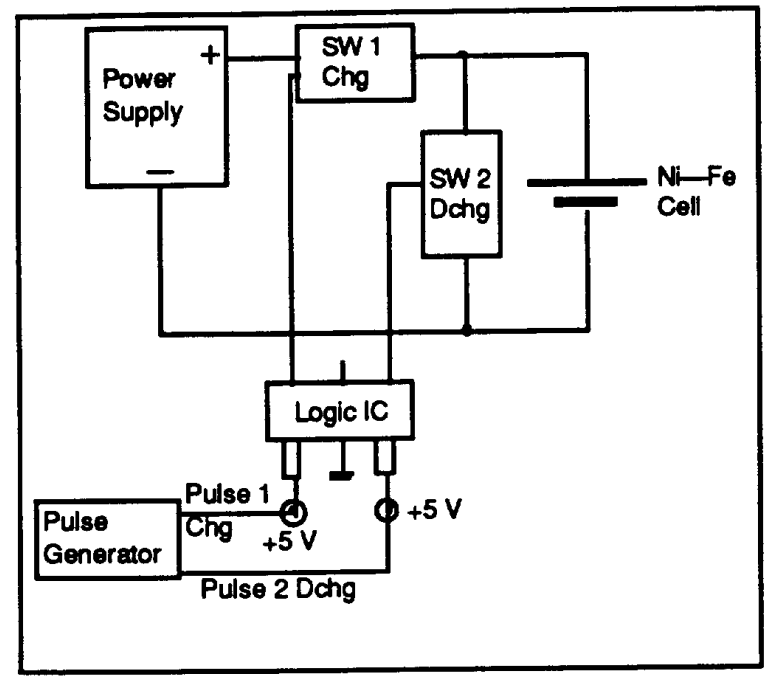

Figure 4. Schematic of circuitry used for pulse charging the $\mathrm{Ni}-\mathrm{Fe}$ Cell.

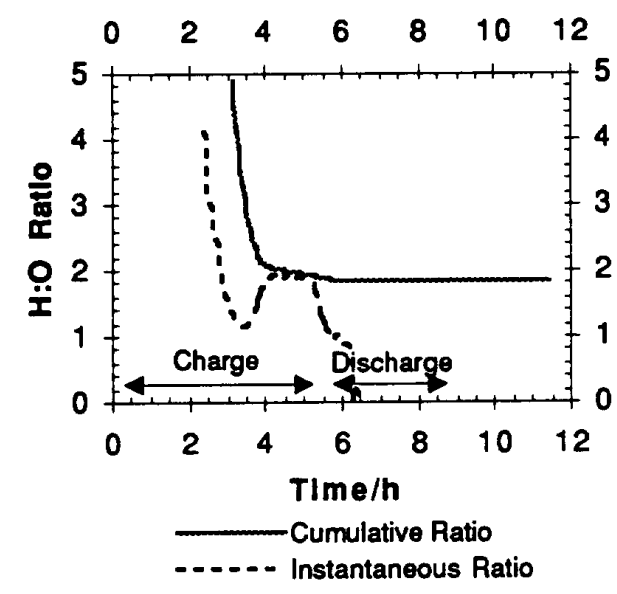

Figure 5. Ratio of $\mathrm{H}_{2}$ to $\mathrm{O}_{2}$ in gas evolved from $\mathrm{Ni}-\mathrm{Fe}$ cell during charge/discharge cycling.

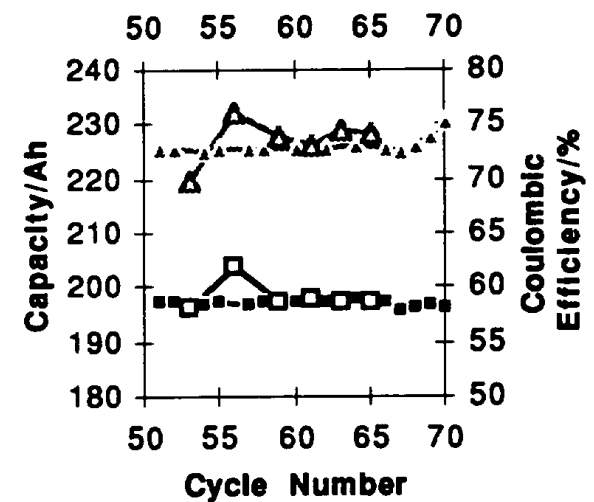

-DDC Capacity - -UURAC Capacity - -DC Efficiency $\rightarrow$-URAC Efficiency

Figure 6. Comparison of capacity and charging efficiency of the $\mathrm{Ni}-\mathrm{Fe}$ cell for DC and URAC charging.

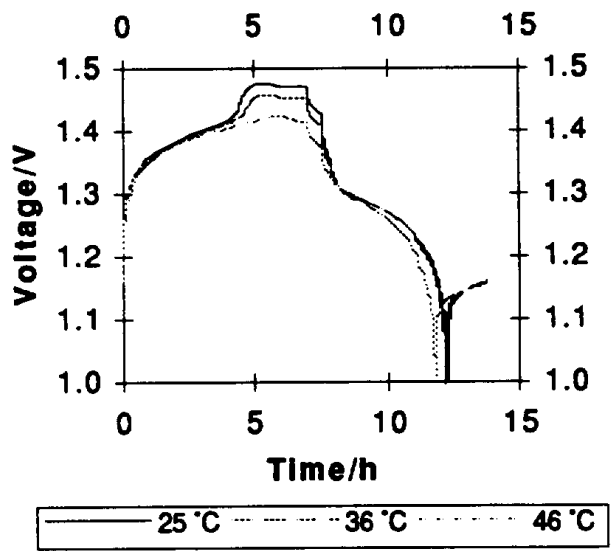

Figure 7. Effect of temperature on voltage of $\mathrm{Ni}-$ MH cells during charge/discharge cycling. 